\section{AB0326 1 REAL-WORLD EXPERIENCE ON SWITCHING ADALIMUMAB ORIGINATOR TO BIOSIMILAR IN INFLAMMATORY ARTHRITIS - A RETROSPECTIVE STUDY}

\begin{abstract}
S. A. Yeoh ${ }^{1}$, K. Saxby ${ }^{2}$, A. Barron ${ }^{1}$, S. Moore ${ }^{2}$, S. Gani ${ }^{3}$, M. Ehrenstein ${ }^{1}$. ${ }^{1}$ University College London, Rheumatology, London, United Kingdom; ${ }^{2}$ University College London Hospitals NHS Trust, London, United Kingdom; ${ }^{3}$ Medicines Efficiencies Programme, North Central London Sustainability and Transformation Partnership, London, United Kingdom
\end{abstract}

Background: The patent for adalimumab originator expired in 2018 in the United Kingdom. Subsequently, four adalimumab biosimilars were launched. National Health Service England undertook a managed market share tender to ensure plurality of suppliers and price competition over the longer term. Each hospital was subsequently allocated a preferred brand of adalimumab biosimilar. Here we describe our experience of switching patients with inflammatory arthritis from adalimumab originator to the biosimilar, ABP 501 in a single centre.

Objectives: To evaluate the proportion of patients successfully switched from adalimumab originator to ABP 501 focusing on drug retention, reasons for remaining on originator and reasons for switching back from biosimilar to originator. Methods: A retrospective analysis was completed on the cohort of 287 rheumatology patients who were prescribed adalimumab originator prior to the switch to ABP 501. Case notes were analysed to identify whether patients remained on biosimilar 24 weeks after switching from originator.

Results: $99 \%$ patients on adalimumab originator (283/287) were switched to ABP 501 within 32 weeks, starting from February 2019. 1\% (4/287) remained on originator due to a confirmed latex allergy, as the needle cover of the ABP 501 pre-filled syringe consists of dry natural rubber. $4 \%$ (12/283) of patients who switched to biosimilar reverted to originator (1 patient per 2 weeks over 24 weeks). $3 \%(9 / 283)$ of patients who switched to biosimilar were no longer receiving any adalimumab therapy. Reasons for ceasing therapy included recurrent infections (4/9) and progression to the next line of biologics/small molecule therapy (5/9). 93\% (262/283) remained stable on ABP 501 (Table). Applications to revert to originator were reviewed by a Biosimilar Steering Group (BSG). The BSG assessment included a review of disease activity, reported symptoms and adverse reactions before and after the switch to biosimilar. Approval to revert to originator occurred in patients who had a clear increase in disease activity or newly reported adverse reactions. If the patient had active disease prior to switch, a change to non-adalimumab therapy would be recommended instead. Of the 12 patients who reverted to originator, $7(58 \%)$ did so due to reduced effectiveness, $3(25 \%)$ due to adverse reactions, and $2(17 \%)$ due to both. Adverse reactions reported within 24 hours of the first injection included nausea, anxiety, insomnia, tinnitus, dizziness, headaches and injection-site reactions. Patients also reported hair loss, fatigue and mouth ulcers. Reported adverse reactions ceased once biosimilar was stopped and/or switching back to originator. All patients who reverted to originator due to reduced effectiveness reported a reduction in disease activity and improvement in symptoms.

Conclusion: The vast majority of patients in our cohort on adalimumab were successfully switched from originator to ABP 501 . The adalimumab biosimilar has been generally well-tolerated. $93 \%$ remained on biosimilar 24 weeks after switching, $4 \%$ have switched back to originator and $3 \%$ have either stopped or changed treatment. Reasons for switching back to originator from biosimilar included adverse reactions, most of which occurred within 24 hours, and also worsening of symptoms.

Table. Baseline characteristics and 6-month outcome of patients who have switched from originator to ABP 501

\begin{tabular}{|c|c|c|c|c|c|}
\hline Baseline characteristics/outcome & $\begin{array}{c}\text { Total } \\
N=283\end{array}$ & $\begin{array}{c}\text { RA } \\
N=90(32 \%)\end{array}$ & $\begin{array}{c}\text { SpA } \\
N=108 \\
(38 \%)\end{array}$ & $\begin{array}{l}\text { PsA } \\
N=77 \\
(27 \%)\end{array}$ & $\begin{array}{l}\text { Other } \\
\mathrm{N}=8 \\
(3 \%)\end{array}$ \\
\hline Mean age (SD) & $49.8(14.6)$ & 58.5 & $43.6(11.0)$ & $\begin{array}{c}48.4 \\
(13.2)\end{array}$ & $\begin{array}{c}46.1 \\
(15.2)\end{array}$ \\
\hline Female, n (\%) & $126(45)$ & $67(74)$ & $29(38)$ & $26(34)$ & $4(50)$ \\
\hline $\begin{array}{l}\text { Reverted to Originator } \\
\mathrm{n} \text { (\% of patients within subgroup) } \\
\text { Reasons for switching back to } \\
\text { Originator }\end{array}$ & $12(4)$ & $4(4)$ & $6(6)$ & $1(1)$ & $1(13)$ \\
\hline Inefficacy & 7 & 1 & 4 & 1 & 1 \\
\hline Adverse reactions & 3 & 2 & 1 & 0 & 0 \\
\hline Both & 2 & 1 & 1 & 0 & 0 \\
\hline $\begin{array}{l}\text { Switched to another biologic agent } \\
\mathrm{n} \text { (\% of patients within subgroup) }\end{array}$ & $5(2)$ & $3(3)$ & $2(2)$ & $0(0)$ & $0(0)$ \\
\hline $\begin{array}{l}\text { Stopped biologics } \\
\mathrm{n}(\% \text { of patients within subgroup) }\end{array}$ & $4(1)$ & $1(1)$ & $1(1)$ & $2(3)$ & $0(0)$ \\
\hline
\end{tabular}

Disclosure of Interests: None declared

DOI: 10.1136/annrheumdis-2020-eular. 1951

\section{AB0327 SERUM IRISIN LEVELS IN HEALTHY WOMEN AND PATIENTS WITH RHEUMATOID ARTHRITIS}

A. Yury ${ }^{1}$, B. Zavodovsky ${ }^{1}$, P. J ${ }^{1}$, S. L ${ }^{1}$, E. Papichev ${ }^{1}$, D. Lavrova ${ }^{1}$

${ }^{1}$ Federal State Budgetary Institution «Research Institute of Clinical and Experimental Rheumatology named after A. B. Zborovsky», Volgograd, Russian Federation

Objectives: to study serum irisin levels in healthy females and patients with rheumatoid arthritis.

Methods: We examined 110 patients with a reliable diagnosis of rheumatoid arthritis (RA). The age of the examined was from 18 to 69 years, all patients were female. The diagnosis of RA was established on the basis of the 2010 EULAR diagnostic criteria. The group of patients included patients with a diagnosis at least one month before the planned screening. As a control group, as well as to create a representation of the normal values irisina level in the blood serum of healthy persons were examined 60 healthy volunteers (all women). In both groups, the level of serum irisin was determined using the enzyme-linked immunosorbent assay by the commercial Irisin ELISA kit.

Results: As a result of measurements in the group of healthy individuals, the average value with the standard deviation used to assess the reliability of the average values was $20.49 \pm 4.82 \mu \mathrm{g} / \mathrm{ml}(\mu \pm \sigma)$. By calculation, a reference interval of $10.85-30.13 \mu \mathrm{g} / \mathrm{ml}$ was determined, defined as $\mu \pm 2 \sigma$. In patients with RA, the level of serum irisin was $14.52 \pm 6.99 \mu \mathrm{g} / \mathrm{ml}(\mu \pm \sigma)$, which is significantly lower than in healthy individuals $(p<0.01)$. Then we divided all patients into 2 groups: group 1 with normal values (66 people), group 2 (44 patients) - with a reduced (less than 10.85 $\mu \mathrm{g} / \mathrm{ml}$ ) level of irisin. In both groups, the dynamics of the level of serum irisin was studied depending on the duration of the disease. Among patients with a disease RA duration of less than 4 years, 16 (24.24\%) patients had a normal level of irisin and $14(31.82 \%)$ had a reduced level (less than $10.85 \mu \mathrm{g} / \mathrm{ml}$ ). Among patients with a disease duration of more than 10 years, $36(54.55 \%)$ patients had a normal level of serum irisin, and a low level was determined in $16(36.36 \%)$ patients $\left(x^{2}=3.568\right.$, $\mathrm{p}=0.168$ ).

Conclusion: According to the data obtained, the normal level of serum irisin in healthy female individuals was $10.85-30.13 \mu \mathrm{g} / \mathrm{ml}$. In patients with RA, the average level of irisin is significantly lower, however, with an increase in the duration of the disease, it tends to normalize.

Disclosure of Interests: None declared

DOI: 10.1136/annrheumdis-2020-eular.1666

\section{Rheumatoid arthritis - non biologic treatment and small molecules}

\section{AB0328 SIMILAR EFFICACY OF TOFACITINIB THERAPY IN BIOLOGIC NAIVE AND HAD PRIOR BIOLOGIC USE HISTORY PATIENTS WITH RHEUMATOID ARTHRITIS (OREL REGISTER)}

E. Nasonov ${ }^{1}$, A. Avdeeva ${ }^{1}$, A. Misiyuk ${ }^{1}$, A. Satybaldyev ${ }^{1}$, V. Sorotskaya ${ }^{2}$, O. Fomina ${ }^{3}$, A. Babaeva ${ }^{4}$, N. Lapkina ${ }^{5}$, A. Lila ${ }^{1}{ }^{1}$ V.A. Nasonova Research Institute of Rheumatology, Moscow, Russian Federation; ${ }^{2}$ Tula State University, Tula, Russian Federation; ${ }^{3}$ Regional Hospital Amur, Amur, Russian Federation; ${ }^{4}$ Volgograd State Medical University, Volgograd, Russian Federation; ${ }^{5}$ Yaroslavl State Medical University, Yaroslavl, Russian Federation

Objectives: To evaluate the efficacy of tofacitinib therapy (TOFA) in biologic naive and had prior biologic use history patients with rheumatoid arthritis (RA) according to OREL register

Methods: Were analyzed the data from Russian national register of patients with RA - OREL treated with TOFA. 138 patients (118 woman, Me;IQR age 55.0 (43.0-63.0) years, disease duration 128.0 (84.0-213.0) months, mean DAS 285.5 (4.6-6.2), SDAI 30.5 (21.4-42.9), positive for ACCP (73\%)/RF (77\%), who were non-responders to MTX at least $15 \mathrm{mg} /$ week and/or other synthetic DMARDs) who received TOFA therapy for more than 1 year were selected for statistical analysis. TOFA used in 26 (18.8\%) pts without DMARDs, combination with MTX in $82(59.4 \%)$ pts, leflunomide in 21 (15.2\%). Low-dose oral corticosteroids $(<10 \mathrm{mg} /$ day prednisone or equivalent) were received by $43(31.2 \%)$ pts TOFA therapy was started in all pts in dose $5 \mathrm{mg}$ BID per os with dose escalation to $10 \mathrm{mg} \mathrm{BID}$ in (86\%) pts.

Results: The use of TOFA was accompanied by a decrease in the disease activity and the level of acute phase reactants (CRP and ESR) after 12, 24 and 48 weeks of therapy, $p<0.05$, table 1 . Depending on the previous treatment with biological DMARDs, all patients were divided into two groups: had prior biologic use history pts (group 1) $(n=51)$ and biologic naïve pts (group 2) $(n=87)$, table 1 . 
Table 1. The dynamics of the disease activity during treatment with TOFA

\begin{tabular}{|c|c|c|c|c|}
\hline Parameters & Weeks & $\begin{array}{l}\text { All patients } \\
(\mathrm{n}=138)\end{array}$ & $\begin{array}{l}\text { Had prior biologic use } \\
\text { history (group 1) }(n=51)\end{array}$ & $\begin{array}{l}\text { Biologic naive } \\
\text { (group 2) }(n=87)\end{array}$ \\
\hline \multirow[t]{4}{*}{ DAS28 } & baseline & $5,5(4,6-6,2)$ & $5,1(4,5-5,9)$ & $5,7(4,8-6,5) \$$ \\
\hline & week 12 & $4,2(3,1-4,8)^{\star}$ & $3,9(2,8-4,8)^{*}$ & $4,4(3,7-4,8)^{\star}$ \\
\hline & week 24 & $3,4(2,7-4,4)^{\star}$ & $3,5(2,4-4,3)^{*}$ & $3,4(2,8-4,5)^{\star}$ \\
\hline & week 48 & $3,3(2,5-4,4)^{\star}$ & $3,2(2,4-4,2)^{*}$ & $3,4(2,7-4,4)^{\star}$ \\
\hline \multirow[t]{4}{*}{ SDAI } & baseline & $30,5(21,4-42,9)$ & $28,6(18,1-36,6)$ & $33,1(22,6-45,9)$ \\
\hline & week 12 & $14,5(7,1-23,3)^{\star}$ & $13,1(5,1-19,1)^{\star}$ & $16,3(9,3-25,6)^{*}$ \\
\hline & week 24 & $10,5(5,1-19,0)^{*}$ & $11,0(5,5-17,6)^{\star}$ & $9,1(4,7-20,4)^{\star}$ \\
\hline & week 48 & $10,3(4,9-17,7)^{\star}$ & $10,2(3,4-15,8)^{\star}$ & $10,9(6,2-18,1)^{\star}$ \\
\hline \multirow[t]{4}{*}{ CDAI } & baseline & $28,2(20,0-37,1)$ & $25,7(17,0-33,7)$ & $30,0(21,5-40,5)$ \\
\hline & week 12 & $14,9(8,0-22,5)^{\star}$ & $13,0(6,8-18,7)^{\star}$ & $16,6(9,0-24,0)^{*}$ \\
\hline & week 24 & $10,0(5,0-18,0)^{*}$ & $11,0(4,7-16,0)^{\star}$ & $9,3(5,0-18,0)^{\star}$ \\
\hline & week 48 & $10,1(5,8-17,0)^{*}$ & $10,4(4,0-16,0)^{\star}$ & $10,0(6,0-17,0)^{\star}$ \\
\hline \multirow[t]{4}{*}{ CRP, mg/l } & baseline & $15,6(6,5-38,0)$ & $15,6(6,0-38,1)$ & $15,4(6,9-36,7)$ \\
\hline & week 12 & $5,5(1,7-12,1)^{\star}$ & $6,4(2,7-10,4)^{\star}$ & $5,2(1,3-12,8)^{\star}$ \\
\hline & week 24 & $4,5(1,0-10,0)^{\star}$ & $5,0(0,8-9,8)^{*}$ & $4,2(1,0-10,0)^{*}$ \\
\hline & week 48 & $4,0(0,7-9,0)^{\star}$ & $2,9(0,6-9,6)^{*}$ & $4,0(0,8-8,9)^{*}$ \\
\hline \multirow[t]{4}{*}{$\mathrm{ESR}, \mathrm{mm} / \mathrm{h}$} & baseline & $32,0(23,0-48,0)$ & $29,0(16,0-37,0)$ & $32,0(23,0-49,0) \$$ \\
\hline & week 12 & $21,0(17,0-33,0)^{\star}$ & $20,0(12,0-33,0)$ & $21,0(17,0-33,0)^{*}$ \\
\hline & week 24 & $21,0(12,0-31,0)^{\star}$ & $13,0(9,0-28,0)$ & $21,0(12,0-31,0)^{*}$ \\
\hline & week 48 & $16,0(10,0-27,0)^{*}$ & $16,0(7,0-30,0)^{*}$ & $16,0(10,0-27,0)^{*}$ \\
\hline
\end{tabular}

${ }^{*} p<0.05$ from baseline; $\$ p<0.05$ between the groups 1 and 2

Patients of the second group had a higher disease activity and ESR before therapy. The use of TOFA was accompanied by a decrease in the disease activity and the level of acute phase reactants (CRP and ESR) in both groups of patients. By week 48 of treatment, no significant difference between the groups according to the disease activity was detected.

In the first and the second group of pts on the 48-th week of therapy remission/ low disease activity was achieved on DAS 28 in $51 \%$ and $43 \%(p=0.57)$, high disease activity on DAS 28 in $12 \%$ and $8 \%(p=0.48)$.

Conclusion: An analysis of the data from the Russian national register of patients with RA demonstrated similar efficacy of TOFA among patients who received and did not receive previous biological therapy.

Disclosure of Interests: Evgeny Nasonov Speakers bureau: Lilly, AbbVie, Pfizer, Biocad, R-Pharm, Anastasia Avdeeva: None declared, Anna Misiyuk: None declared, Azamat Satybaldyev: None declared, Valentina Sorotskaya: None declared, Oxana Fomina: None declared, Aida Babaeva: None declared, N Lapkina: None declared, Alexander Lila: None declared DOI: 10.1136/annrheumdis-2020-eular.3052

\section{AB0329 1 PHYSICIANS' PRE-LAUNCH AWARENESS AND CONCERNS WITH PIPELINE JANUS KINASE INHIBITORS (JAKIS) VERSUS TOFACITINIB AND BARICITINIB IN RHEUMATOID ARTHRITIS IN THE UNITED STATES AND EUROPE}

\section{Baldock ${ }^{1}$, G. Giannakopoulou ${ }^{1} .{ }^{1}$ Ipsos MORI, London, United Kingdom}

Background: Clinical data regarding use of tofacitinib and baricitinib in rheumatoid arthritis patients have recently posed safety concerns, with regulatory bodies suggesting limiting use of higher dosages. Investigating physicians' awareness and views of each of these products leading up to their launch, as well as the physicians' patient characteristics, may provide evidence of how pipeline JAKis could be received in the treatment landscape once approved. Objectives: The objective of the study was to investigate awareness and anticipated concerns of upcoming versus already launched JAKis among a sample of treating rheumatologists in the US and EU5 countries, and assess potential correlation between sampled physicians' views on JAKis and their managed patient characteristics.

Methods: A multi-country, multi-center online medical chart review study of patients with RA was conducted across 2011 - 2019 among rheumatologists in hospitals and private practices to collect de-identified data on a sample of patients who were recently treated with a biologic/JAKi in the USA \& EU5 (UK, France, Italy, Spain, Germany). Physicians were screened for duration of practice (3-30 years) and patient volume ( $\geq 2$ RA biologic/JAKi patients per week) and recruited from a large, geographically representative access panel. Patient charts were recorded for the next 5 eligible patients seen during the screening period. Respondents abstracted patient demographics and personal awareness and concerns for drugs in development. Sites waived local ethics review owing to collection of retrospective de-identified data. Data were analyzed using descriptive statistics.

Results: In Q1 $19,56.2 \%$ and $56.2 \%$ of sampled US physicians were aware of upadacitinib (upa) and filgotinib (filgo), respectively ${ }^{1}$. Prior to US launch, tofacitinib (tofa) and baricitinib (bari) achieved respective awarenesses of 89.9\% (Q4 11, $\mathrm{n}=109)^{2}$ and 85.2\% (Q2 17, $\left.\mathrm{n}=101\right)^{3}$. Among 262 sampled EU5 rheumatologists, pre-launch awareness in of upa and filgo in Q1 19 was $46.2 \%$ and $45.8 \%{ }^{1}$, while for tofa and bari it was $46.2 \%$ and $45.8 \%$, respectively (Q2 $16, n=380)^{4}$. 'Poor safety profile' was cited as a common anticipated concern for upa and filgo, $9.9 \%$ of sampled physicians aware of upa $(n=121)$ and $7.5 \%$ of those aware of filgo $(n=120)^{1}$, with the respective scores for tofa and bari prior to their launch being $16.9 \%(n=296)$ and $14.5 \%(n=227)^{4}$. Sampled patient characteristics in each physician segment (upa concerned $n=449$ patients non-concerned, $\mathrm{n}=155$ patients; filgo concerned, $\mathrm{n}=454$ patients /non-concerned, $\mathrm{n}=145$ patients) included: (a) age in years 54.6/51, $\mathrm{p}<0.01 ; 53.9 / 51.2$, $\mathrm{p}<0.05$ (b) retired employment status $31 \% / 20.6 \%, p<0.05 ; 29.5 \% / 20 \%, p<0.05$

Conclusion: In this sample, upa and filgo achieved lower awareness scores, compared to tofa and bari prior their launch. Sampled EU5 physicians were less concerned with upa and filgo's safety profiles, than for the other two JAKis before launch. Sampled physicians holding concerns with upa/filgo manage significantly older patients and a significantly higher number of retired patients. Further investigation using comparator cohort is warranted

References:

[1] Ipsos Global Rheumatoid Arthritis Therapy Monitor (Q1 2019, 262 sampled rheumatologists in the EU and 115 sampled rheumatologists in the US reporting on a sample of RA patients seen in their practice; data collected online).

[2] Ipsos Global Rheumatoid Arthritis Therapy Monitor (Q4 2011, 109 sampled rheumatologists in the US reporting on a sample of RA patients seen in their practice; data collected online)

[3] Ipsos Global Rheumatoid Arthritis Therapy Monitor (Q2 2017, 101 sampled rheumatologists in the US reporting on a sample of RA patients seen in their practice; data collected online)

[4] Ipsos Global Rheumatoid Arthritis Therapy Monitor (Q2 2016, 380 sampled rheumatologists in the EU reporting on a sample of RA patients seen in their practice; data collected online)

(C) Ipsos 2020, all rights reserved

Disclosure of Interests: None declared

DOI: 10.1136/annrheumdis-2020-eular.2194

\section{$\mathrm{AB} 0330$ HIGH REMISSION RATES IN RA - REAL LIFE DATA FROM BARITICINIB}

S. Bayat ${ }^{1}$, K. Tascilar ${ }^{1}$, V. Kaufmann ${ }^{1}$, A. Kleyer ${ }^{1}$, D. Simon ${ }^{1}$, J. Knitza ${ }^{1}$,

F. Hartmann 1 , S. Adam ${ }^{1}$, A. Hueber ${ }^{2}$, G. Schett ${ }^{1} .{ }^{1}$ University Hospital Erlangen; Department of Internal Medicine ${ }^{3}$ - Rheumatology and Immunology, Friedrich-Alexander University (FAU) Erlangen-Nürnberg, Erlangen, Germany; ${ }^{2}$ Sozialstiftung Bamberg; Rheumatology, Bamberg, Germany

Background: Recent developments of targeted treatments such as targeted synthetic DMARDs (tsDMARDs) increase the chances of a sustained low disease activity (LDA) or remission state for patients suffering rheumatoid arthritis (RA). tsDMARDs such as baricitinib, an oral inhibitor of the Janus Kinases (JAK1/JAK2) was recently approved for the treatment of RA with an inadequate response to conventional (CDMARD) and biological (bDMARD) therapy. $(1,2)$.

Objectives: Aim of this study is to analyze the effect of baricitinb on disease activity (DAS28, LDA) in patients with RA in real life, to analyze drug persistance and associate these effects with various baseline characteristics.

Methods: All RA patients were seen in our outpatient clinic. If a patient was switched to a baricitinib due to medical reasons, these patients were included in our prospective, observational study which started in April 2017. Clinical scores (SJC/TJC 76/78), composite scores (DAS28), PROs (HAQ-DI; RAID; FACIT), safety parameters (not reported in this abstract) as well as laboratory biomarkers were collected at each visit every three months. Linear mixed effects models for repeated measurements were used to analyze the time course of disease activity, patient reported outcomes and laboratory results. We estimated the probabilities of continued baricitinib treatment and the probabilities of LDA and remission by DAS-28 as well as Boolean remission up to one year using survival analysis and explored their association with disease characteristics using multivariable Cox regression. All patients gave informed consent. The study is approved by the local ethics.

Results: 95 patients were included and 85 analyzed with available follow-up data until November 2019. Demographics are shown in table 1. Mean follow-up duration after starting baricitinib was 49.3 (28.9) weeks. 51 patients $(60 \%)$ were on monotherapy. Baricitinib survival $(95 \% \mathrm{Cl})$ was $82 \%(73 \%$ to $91 \%$ ) at one year. Cumulative number (\%probability, $95 \% \mathrm{Cl}$ ) of patients that 